\title{
Droplet Size Characterization of the New Type Complete Fluidic Sprinkler
}

\author{
Frank Agyen Dwomoh ${ }^{1,2}$; Yuan Shouqi ${ }^{1}$; Li Hong ${ }^{1}$ \\ ${ }^{1}$ (Research Centre of Fluid Machinery Engineering and Technology, Jiangsu University, P. R. China) \\ ${ }^{2}$ (Mechanical Engineering Department, School of Engineering, Koforidua Polytechnic, Ghana.)
}

\begin{abstract}
Accurate knowledge of droplet size characteristics of a given sprinkler will aid selection for design of sprinkler irrigation systems. In this paper, the droplet size distribution characteristics of the new type complete fluidic sprinkler have been experimentally determined using a Thiess Clima Laser precipitation monitor under in door conditions. The experimental data were accessed using the RS 48/422 interface of the Laser precipitation monitor. Droplet diameter measurements were performed for three manufacturers recommended operating pressure conditions. Comparisons of the percentage of droplets at the three different operating conditions are presented. The cumulative numeric frequency and cumulative volumetric frequency curves indicate that about $50 \%$ of the droplets had diameter less $0.5 \mathrm{~mm}$ and $50 \%$ of the water volume consisted of droplets with diameter less than $2 \mathrm{~mm}$ at most distances. The results are similar to those obtained by earlier researchers who used different sprinkler-types and droplet size measurement methods and hence proves the validity of the measurements.
\end{abstract}

Keywords: Droplet size, Characterization, Wall attachment Fluidic Sprinkler, Laser precipitation monitoring

\section{Introduction}

An important performance characteristic of sprinkler water application quality is the droplet size distribution. According to Molle (2002), droplet size distribution determines the sensitivity of a sprinkler's water distribution to wind, evaporation and its impact on the crop or soil surface and slope. Sprinkler drop sizes can also influence irrigation system design, irrigation uniformity and efficiency (DeBoer et., 2001; Bernuth and Gilley, 1984). Droplet size characterization is important in sprinkler irrigation for three major reasons.

Solomon et al (1996) showed that wind affects the uniformity and efficiency of a sprinkler system by distorting the distribution pattern of sprinkler water application. The degree of distortion is dependent on wind speed and direction as well as the droplet sizes in the distribution. Wind exerts a force which is proportional to the square of the droplet diameter, while the inertia of the droplet resisting the wind's force is proportional to the droplet's mass - in effect wind tends to easily distort sprinkler droplets distributions which have more small droplets.

During sprinkler irrigation, apart from the climate demand, the amount of water that evaporates from a droplet depends on how long the drop remains in the air and on the surface area of the water droplet (Uddin et al. 2010, Smajstrla and Zazueta, 2006; Solomon et al., 1985). The time the droplet remains in the air and the surface area of the droplet are all functions of the drop size. For a unit volume of water, the surface area doubles, as the droplet diameter decreases by half. And since evaporation rate increases with increasing exposed surface area, evaporation rate increases as droplet size decreases if all other factors remain constant. The time available for droplet evaporation is the time beginning from when a water droplet leaves the nozzle till it falls on the ground or crop surface (Holterman, 2003). When this time is extended long enough due to suspension of drops by wind, small droplets evaporate before they fall to the ground (Smajstrla and Zazueta, 2006). The extent of wind drift is also influenced by the droplet size (Solomon et al., 1996; Dadio and Wallender, 1985).

Thirdly, large droplets may lead to erosion of the soil resulting from a reduction in water infiltration rate. This is because large droplets possess high kinetic energy and on impart they disrupt soil surface, especially in soils with crustiness problems, leading to sealing of the soil surface (Kincaid, 1996). For this reason, it is becoming convenient for irrigators to reduce runoff and erosion by converting from sprinklers that emit large drops to those that emit smaller droplets (Friso and Bortolini, 2010; Chi, 2010). Research has shown that droplet formation is mainly affected by pressure, nozzle size and configuration (Zhu et al., 2009; Derrel et al., 2007; Friso and Bortolini, 2010; Hills and Gun 1989; Li and Yu, 1994).

The complete fluidic sprinkler is a relatively new type of rotating sprinkler head invented in China. It has the prospects of being easy to construct, low-loss of energy and low price (Zhu et al, 2012; Dwomoh et al. 2013). Over the years, several theoretical, numerical and experimental studies have been conducted which have helped to improve upon the structural and hydraulic performance of the complete fluidic sprinkler. However, knowledge of the fluidic sprinkler's droplet characterization is limited and un-popular. With the rising concern for sustainability and efficiency in resource use in irrigation, selection of a specific sprinkler package for a 
particular irrigated field will be aided by the knowledge of the drop size in future, according to Kincaid et al (1996). Manufacturers are interested in knowing what droplet sizes, in what percentage or volumes and where they are deposited for comparison of products, evaluation of designs and to predict the effects of operating conditions such as pressure. The specific objective of this work is to characterize the droplet size distribution of the complete fluidic sprinkler to highlight its hydraulic performance characteristics.

\section{Materials And Method}

Experiments were conducted under no wind conditions in the Indoor Sprinkler Laboratory facility of Jiangsu University as shown in Figure 1. Droplet size measurements were performed using a Thies Clima Laser Precipitation Monitor (TCLPM) manufactured by Adolf Thies GMBH \& Co. KG, Gottingen, Germany. The specifications of the nominal measuring area are $228 \mathrm{~mm}$ long, $20 \mathrm{~mm}$ wide with a thickness of $0.75 \mathrm{~mm}$. The TCLPM works such that a laser-optical beaming source produces a parallel light-beam (infrared, 785nm). A photo diode with a lens is situated on the receiver side to measure the optical intensity after transformation into electrical signals. When a water drop falls through the measuring area, the receiving signal is reduced. The diameter of the drop is calculated from the amplitude of the reduction, while the drop velocity is calculated from the duration of the reduced signal.

The 20PXH model of the fluidic sprinkler was used. The nozzle height above the TCLPM was $0.8 \mathrm{~m}$ and the height of the TCLPM above ground level was $0.8 \mathrm{~m}$. Drop diameter measurements were performed at the manufacturer's recommended operating pressure conditions of 250, 300 and $350 \mathrm{kPa}$. For each operating pressure, the drop size distributions were measured at $2 \mathrm{~m}$ interval along a radial transect starting at $2 \mathrm{~m}$ from the sprinkler and ending at the farthest possible distance droplets could be collected. For each droplet diameter measurement, the sprinkler was allowed to rotate over the TCLPM for at least five times to ensure sufficient number of drops passed through the measuring area.
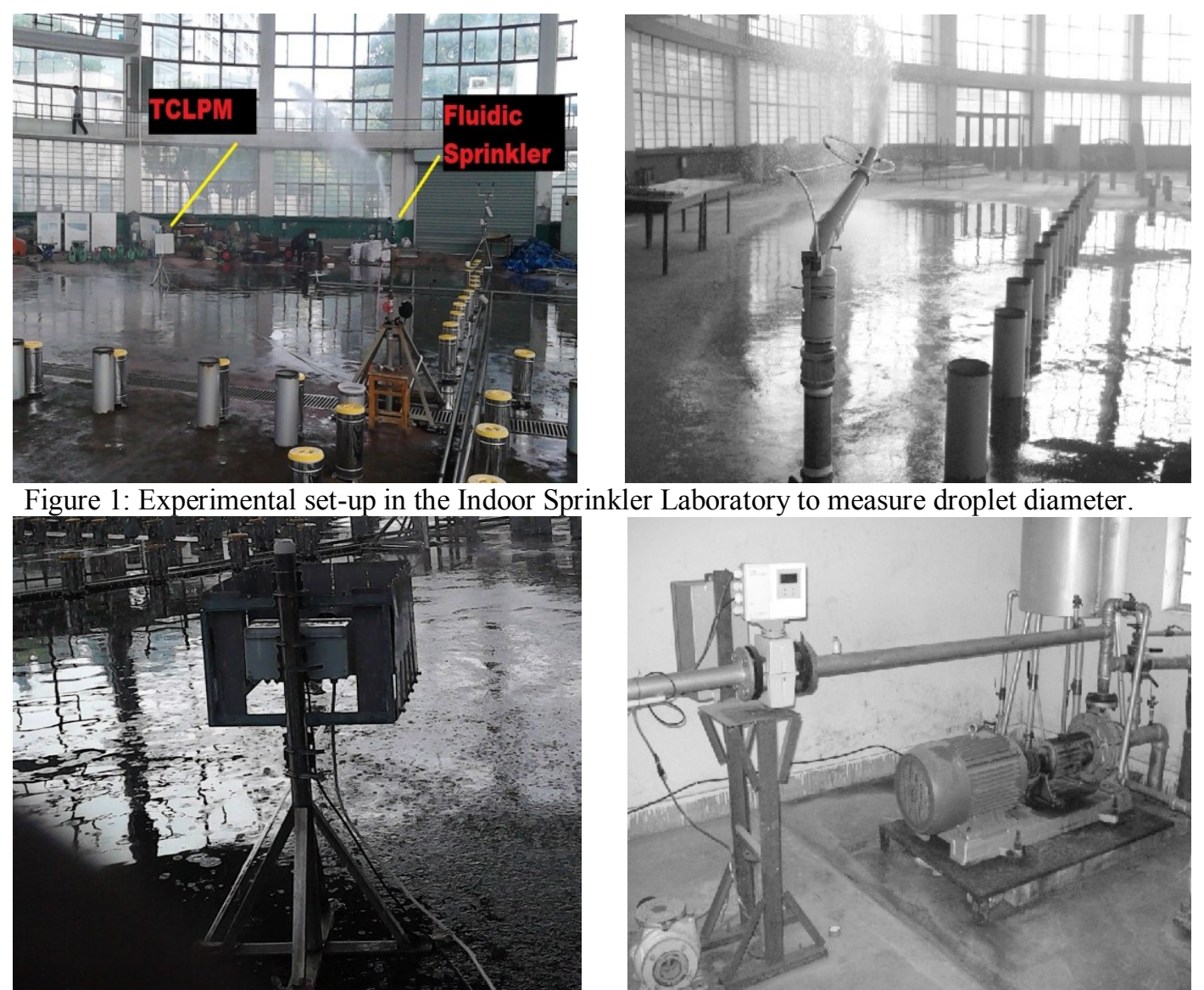

Figure 2: TCLPM instrument, Pump and Flow meter set-up in the Sprinkler Laboratory

At the far end of the range, beyond $90 \%$ of maximum throw distance, due to the difficulty in getting enough samples for measurements, ten rotations were allowed over the measuring area to ensure enough samples were captured. By means of an RS 485/422 interface, the measured data were accessed on a computer. The TCLPM used for this experiment has a drop diameter measurement range from 0.125 to $8.5 \mathrm{~mm}$ with increments of $0.125 \mathrm{~mm}$. Data were ordered into cells according to the drop diameter and their corresponding 
velocity. Employing the error reduction approach used by Solomon et al. (1996) and Kincaid et al. (1996), drop velocities that exceeded \pm 2 standard deviation of the average velocity for drop diameter at the measured location were discarded from the data set. A pressure gauge located between the pressure regulator and the sprinkler nozzle was used to configure and record the operating pressure. The operating pressures were within $\pm 5 \mathrm{kPa}$ of the nominal pressure configuration.

\section{Results And Discussion}

From the raw droplet distribution data, the numeric median diameter (NMD) and volumetric median diameter (VMD) were estimated. The NMD and VMD are diameters corresponding to the median of the distribution of droplet diameter categorized into numbers and volume, respectively (Molle et al, 2012) and subsequently, the cumulative numeric frequency $(\mathrm{CNF})$ and cumulative volumetric frequency $(\mathrm{CVF})$ calculated.

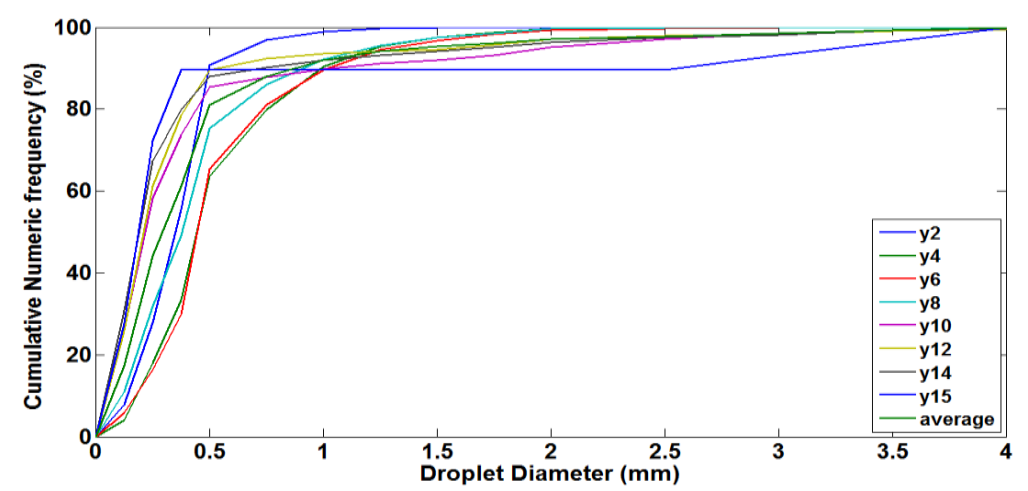

Figure 3: Cumulative Numeric Frequency with droplet diameter along a radial transect for a 20PXH fluidic sprinkler at $300 \mathrm{kPa}$. (y2, y4 ..,y15 represent distances of $2 \mathrm{~m}, 4 \mathrm{~m} \ldots, 15 \mathrm{~m}$ from the nozzle, respectively).

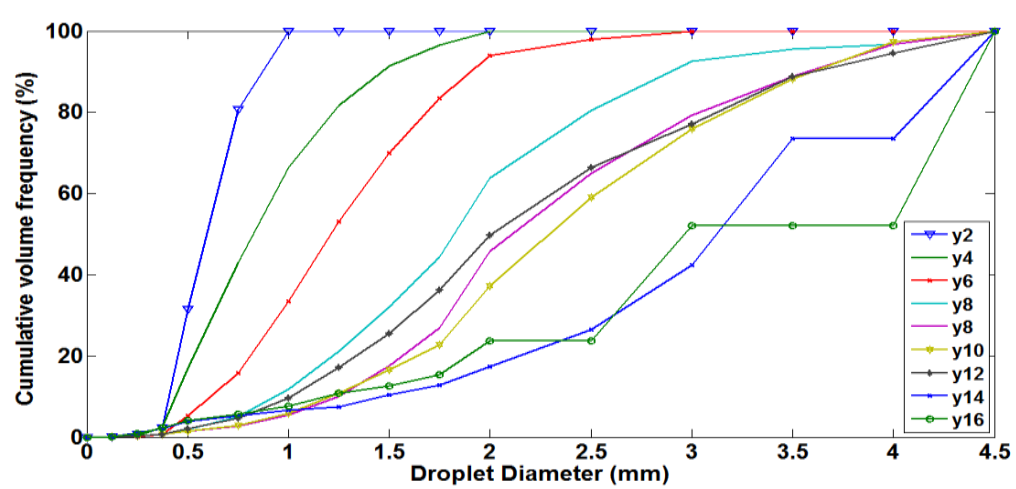

Figure 4: Cumulative Volumetric Frequency with droplet diameter along a radial transect for a 20PXH fluidic sprinkler at $300 \mathrm{kPa}$. (y2, y4...,y16 represent distances of $2 \mathrm{~m}, 4 \mathrm{~m} . . ., 16 \mathrm{~m}$ from the nozzle, respectively).

Figure 3 and Figure 4 present the CNF and CVF curves, respectively. The figures indicate that at any given distance from the sprinkler, there is a statistical distribution of droplet diameter and not a specific diameter as assumed in the ballistic model. The assumption of a definite diameter at a given distance away from the sprinkler in the ballistic model therefore simplifies the real situation for modeling purposes. It can also be noted that at most distances from the sprinkler, the number of droplets in smaller diameters are more compared to those in larger diameters. This goes to support the hypothesis that droplet formation is a continuous process along the jet trajectory (Bradley et al., 2013; Sudheera and Panda, 2000).

The CNF curves (Figure 3) at various distances from the sprinkler nozzle are more homogeneous compared to the CVF curves (Figure 4) which exhibit high variability in statistical distribution. A comparison of CNF and CVF curves indicate that about $50 \%$ of the droplets had a diameter $<0.5 \mathrm{~mm}$ for the CNF and $50 \%$ of the water volume consisted of droplets with diameter $<2 \mathrm{~mm}$ at most distances. The above observations are similar to those obtained by earlier researchers who used different sprinkler-types and hence proves the validity of the measurements (Vories et al., 1987; Montero et al., 2003; Molle, 2002; Friso and Bortolini, 2010).

Table 1 shows the percentage of droplets within a mean diameter at three different operating pressures. From the data, higher percentages of larger diameters were created at lower operating pressures. Conversely high operating pressures resulted in creating a greater portion of droplets in the smaller diameter domain. 
Table 1. Comparison of percentage of droplets at three different operation pressures

\begin{tabular}{ccccccc}
\hline Pressure & \multicolumn{5}{c}{ Percentage of Droplets within a Mean Diameter } \\
\cline { 2 - 7 } $\mathrm{kPa}$ & $0.5 \mathrm{~mm}$ & $1 \mathrm{~mm}$ & $1.5 \mathrm{~mm}$ & $2 \mathrm{~mm}$ & $2.5 \mathrm{~mm}$ & $3 \mathrm{~mm}$ \\
\hline 250 & 11.9 & 15.8 & 14.8 & 18.7 & 14.3 & 24.5 \\
300 & 6.8 & 16.7 & 12.5 & 16.1 & 9.8 & 11.1 \\
350 & 11.4 & 17.5 & 25.7 & 15.7 & 9.4 & 9.6 \\
\hline
\end{tabular}

IV. Conclusions

The droplet size characterizations of the complete fluidic sprinkler have been determined under indoor conditions, using a Thies Clima Laser Precipitation Monitor. The percentage distributions of droplet size formation along radial transect for different operating pressures have been indicated to aid sprinkler selection and operation. A comparison of cumulative numeric frequency and cumulative volumetric frequency curves indicate that about $50 \%$ of the droplets had diameter less $0.5 \mathrm{~mm}$ and $50 \%$ of the water volume consisted of droplets with diameter less than $2 \mathrm{~mm}$ at most distances. In general the results obtained confirm the findings of earlier researchers who used different sprinkler types and methods on the realities of sprinkler droplet formation.

\section{Acknowledgements}

The authors highly acknowledge the support from students of the Sprinkler Group of the Research Centre of Fluid Machinery and Engineering, Jiangsu University for assistance in conducting the experiment. Financial support provided by the Program for National Hi-tech Research and Development (863 Program, No. 2011AA100506) and Program No. 2011GB2C100015 of China, are gratefully acknowledged.

\section{References}

[1] Bernuth, R.D. von; Gilley, J.R. (1984). Sprinkler droplet size distribution estimation from single leg test data. Transactions of the ASAE, 27, 1435-1441.

[2] Bradley A. K., Troy W. W., David L. B. (2013). Comparison of Sprinkler Droplet Size and Velocity Measurements using a Laser Precipitation Meter and Photographic Method. The American Society of Agricultural and Biological Engineers, Paper number 131594348 .

[3] Chi D. (2010). Irrigation and Drainage. Chapter 3 Irrigation Techniques. 41-65. ISBN 978-7-5084-7279-9.

[4] Dadio C., Wallender W. (1985). Droplet size distribution and water application with low-pressure sprinkler. Transactions of the ASAE, 28, 511-516.

[5] Derrel L. M., Dennis C. K., et al. (2007). Chapter 16: Design and Operation of sprinkler systems in Design and Operation of Farm Irrigation Systems, 2nd Edition.

[6] DeBoer, D. W., M. J. Monnens, D. C. Kincaid (2001). Measurement of sprinkler droplet size. Applied Engineering in Agriculture 17.1: 11-15.

[7] Dwomoh F. A., Yuan S., Li H. (2013). Field Performance Characteristics of Fluidic Sprinkler. Applied Engineering in Agriculture. 29(4): 529-536.

[8] Friso D.; Bortolini L. (2010). Calculation of sprinkler droplet-size spectrum from water distribution radial curve. International Journal of Energy Technology, 24, 1-11.

[9] Hills D. J., Gun Y. (1989). Sprinkler volume droplet diameter as a function of pressure. Transactions of the ASAE, 32:471-476.

[10] Holterman H. J. (2003). Kinetics and evaporation of water drops in air. IMAG report 2003-12. Wageningen UR July 2003.

[11] Kincaid D. C., Solomon K. H., Oliphant J. C. (1996). Drop size distribution for irrigation sprinklers, Transactions of the ASAE, 39 (3), 839-845.

[12] Li, J., Kawano, H., Yu, K. (1994). Droplet size distributions from different shaped sprinkler nozzles. Transactions of the ASAE, 37, 1871-1878.

[13] Molle B., Tomas S., Hendawi M., Granier, J. (2012). Evaporation and wind drift losses during sprinkler irrigation influenced by droplet size distribution. Irrigation and Drainage 61: 240-250.

[14] Molle B (2002). Characterizing droplet distribution of an irrigation sprinkler water application. In Food production, poverty alleviation and environmental challenges as influenced by limited water resources and population growth. Volume $1 \mathrm{~A}$. 18th International Congress on Irrigation and Drainage, Montréal, Canada, 1-19.

[15] Montero J., Tarjuelo J. M., Carrión P. (2003).Sprinkler droplet size distribution measured with an optical spectropluviometer Irrigation Science. Volume 22, Issue 2, 47-56

[16] Solomon K. H., Zoldoske D. F., Oliphant J. C. (1996). Laser Optical Measurement of Sprinkler Drop Sizes. Center for Irrigation Technology. Standards Notes.

[17] Solomon K.H., Kincaid D. C., Bezdek J.C. (1985). Drop size distribution for irrigation spray nozzles. Transactions of the ASAE, 28(6), 1966-1974.

[18] Sudheera K.P., Panda R.K. (2000). Digital image processing for determining drop sizes from irrigation spray nozzles. Agricultural Water Management 45, 159-167.

[19] Smajstrla, A. G., Zazueta, F. S. (2006). Evaporation loss during sprinkler irrigation.

[20] Uddin, J., Smith, R., Hancock, N., et al. (2010). Droplet evaporation losses during sprinkler Irrigation: an overview. Presented at: Australian Irrigation Conference and Exhibition, 'One Water Many Features', Sydney, Australia, 8-10.

[21] Vories, E. D., Von Bernuth, R. D., Mickelson, R. H. (1987). Simulating sprinkler performance in wind. Journal of Irrigation and Drainage Engineering, 113(1), 119-130.

[22] Zhu, X. Y., Yuan S., Liu J. (2012). Effect of sprinkler head geometrical parameters on hydraulic performance of fluidic sprinkler. Irrigation and Drainage Engineering. 138 (11), 1019-1026. 